
$\$$ Research Square
Preprints are preliminary reports that have not undergone peer review.
They should not be considered conclusive, used to inform clinical practice,
or referenced by the media as validated information.

\title{
The Students' Attitudes Towards Women'S Childbirth Experience - Development and Validation of a Questionnaire for Health Sciences Students (Cave-St)
}

\author{
Cristóbal Rengel-Díaz \\ Hospital Universitario de Malaga \\ Olga Riklikiene \\ Lithuanian University of Health Sciences \\ Gillian Thomson \\ University of Central Lancashire \\ Olga Cazorla-Granados \\ Universidad de Malaga \\ Wilson Abreu \\ University of Porto \\ Gozde Gokce Isbir \\ Mersin Universitesi \\ Sigridur Sia Jonsdottir \\ University of Akureyri \\ Sigfridur Inga Karlsdottir \\ University of Akureyri \\ Joan Lalor \\ University of Dublin Trinity College \\ Emesto Gonzalez-Mesa ( $\nabla$ egonzalezmesa@gmail.com ) \\ Universidad de Malaga Facultad de Medicina https://orcid.org/0000-0002-7106-092X
}

\section{Research article}

Keywords: Students'attitude, Perinatal education, Childbirth, Questionnaire development

Posted Date: August 31st, 2020

DOl: https://doi.org/10.21203/rs.3.rs-45485/v1

License: (c) (1) This work is licensed under a Creative Commons Attribution 4.0 International License. Read Full License 


\begin{abstract}
BACKGROUND: The purpose of this study is to report on the validation process of the Spanish version of a questionnaire that explores health science students' attitudes towards women's childbirth experiences. This questionnaire could help inform education programs to enhance the quality of womanprofessional interactions, and to improve women's experiences of childbirth.
\end{abstract}

METHODS: A standardised procedure for the development and validation of the questionnaire included: item development and psychometric pre-validation, Cronbach's Alpha and split-half coefficients calculation, test-retest and item-total correlation for the reliability analysis. Content validity was undertaken by Delphi method with sixteen panelists over two rounds. We determined the factor structure and refined and validated the questionnaire according to the responses of a cohort of 160 students using principal components factor analysis with varimax rotation.

RESULTS: A 52-items questionnaire CAVE-st: (acronym for cuestionario de actitudes sobre vivencias y experiencias en el parto) was developed and validated. The questionnaire had a high construct validity, with a Cronbach's alpha $>0.92$. The intraclass correlations $(0.80)$ indicated adequate test-retest reliability. The results of the exploratory factor analysis revealed fourteen latent components that explained more than the $70 \%$ of the observed total variance.

CONCLUSIONS: The Spanish version of the questionnaire CAVE-st has been developed and validated. Its psychometrics indicate that it is a valid and reliable tool to assess health sciences students' attitude towards women's childbirth experience. Further work to translate and adapt the instrument in other cultures and languages will be undertaken.

\title{
Background
}

Beyond strictly clinical aspects, the content and the quality of interpersonal communication between health professionals and patients is directly related to patient care-related outcomes (1). In the experience of childbirth, aside from women being provided with insights into objective complications, women's perception of the verbal and non-verbal behaviours that health care providers display impacts on their experience of pregnancy and childbirth (2). A growing body of research reports that inadequate-sometimes disrespectful, abusive or even violent-care during pregnancy, childbirth or the postpartum period are specific risk factors for birth-related trauma (3-6). Many women remember childbirth as an adverse event, between $10-48 \%$ recall it as a traumatic event, and $1-6 \%$ go on to develop post-traumatic stress disorder (7-11); with poor interactions with care providers identified as a key cause of women's frustration and psychological distress (5). While some variables related to women's negative experiences of childbirth, such as perinatal psychological distress, depression and other mood disorders, are often of unknown and unpredictable etiology, those related to interpersonal interactions with health professionals are modifiable, and can be improved (12).

The World Health Organization (13) highlights the need to direct efforts and educational resources towards improving the quality of perinatal care and eliminating inappropriate practices, urging that women must be respected, informed and involved in the decision making process during pregnancy and childbirth. To achieve this aim, graduate and postgraduate health science students need to acquire clinical skills, as well as interpersonal skills that include how to provide empathic, dignified and respectful care with pregnant and postnatal women $(14,15)$. While methods to teach clinical and technical skills into the physiology and physiopathology of pregnancy and childbirth are generally straightforward, how to improve the quality of woman-provider interactions is less developed. Health professionals underlying attitudes, and understanding of the needs of pregnant and laboring women play a key role in terms of how care is provided (5). This therefore raises important questions as to what information healthcare students receive as part of their professional training, and whether further psychosocial education is needed.

The aim of this study is to report on the validation process of the Spanish version of a questionnaire to explore graduate and postgraduate health sciences students (nursing, midwifery, obstetrics, paediatrics, etc) attitudes towards women's childbirth experiences. It was considered that this questionnaire could help identify important insights into how health sciences education programs could be improved, and ultimately to help improve women's experiences of childbirth.

\section{Methodology Questionnaire development}

As there was no existing questionnaire in this area, we consulted with academics and clinicians from various European universities (Spain, Iceland, Lithuania, Portugal, Turkey and UK) who proposed a total of 100 items for the new instrument. The selection of items was based on current research, best practice guidelines in childbirth care, and experts' professional and academic backgrounds. The experts included researchers and lecturers in the fields of nursing, midwifery, psychology, anthropology, medicine and perinatal care. After all items had been collected, these were re-shared for further discussion and for their suitability to be assessed.

The items were then grouped into key categories: knowledge about care and attention during normal childbirth; beliefs about pain during delivery; autonomy and authority of the mother; priorities related to optimising the foetus's well-being; support during delivery; professional interactions with laboring women including authorization to intervene, respecting women's decisions, respecting women's physiology and the need to identify oneself as a student; knowledge of the factors that cause obstetric trauma; ability to identify birth trauma, and feelings towards the mother during labour. In order to develop a common tool, a decision was made to validate the standard version in Spanish and later adapt it to other cultures and languages.

\section{Delphi Method}


A consensus Delphi approach was used to validate the questionnaire $(16,17)$. A panel of experts from multi-professional backgrounds were appointed to analyse the coherence, clarity and relevance of the proposed items, and to suggest other relevant items that had not been considered. The panel comprised sixteen professionals, including psychiatrists, psychologists, nurses, midwives and gynaecologists, who were of different ages, and from different regions of Spain. All the professionals had a teaching or clinical profile, or both, and all were professionally active.

An online questionnaire was developed, with experts asked to rate all the initial items $(n=100)$ using 5 point Likert scales of strongly disagree/not relevant at all, disagree/not relevant, neutral, agree/relevant, strongly agree/very much relevant. Two rounds of anonymous questionnaires were shared; after the first round, information was provided on the overall results, with experts then asked to rate the list of questions again. Any item which received $80 \%$ agreement for any of the three levels of criteria were retained. Further means to assess the clarity of the questions and questionnaire instructions was also undertaken, with an on-line version of the questionnaire tested on a small group of subjects.

Once the questionnaire prototype was completed, the next step was a field test with a larger sample group. All the final-year medical students at the University of Malaga were invited to participate via an internet link to the questionnaire. The Cronbach's alpha coefficient and Gutman's split-half coefficient were used to measure the internal consistency of the scoring of the questionnaire. The ceiling and floor effects were checked, and the items that reduced the overall consistency were excluded.

The reliability of the instrument was undertaken using the test-retest method with students from the University of Malaga. Students were invited to complete the online questionnaire twice, at 14 days apart. The Kaisser Meyer Olkin (KMO) test and the Barlett's test of sphericity were performed to assess the adequacy of an exploratory factor analysis. An exploratory factor analysis was then conducted using the analysis of the main components of the scale and the Varimax method and orthogonal rotation was used to identify latent factors that explained the observed variance. Figure 1 shows the development and validation process of the questionnaire.

\section{Ethics}

Prior authorization to issue the questionnaire to students was obtained from the ethics committee at University of Malaga. When opening the link to the questionnaire, participants were provided with information about the aims and purpose of the study, and how privacy, anonymity, and confidentiality was ensured. Participants were asked to check a box to indicate their consent to participate.

\section{Results}

\section{Outcomes from Delphi panel and the assessments}

Table 1 shows the main characteristics of the experts that took part in the Delphi method. The average levels of agreement were 80.6, 81.0 and 81.6, and 89.7, 93.5 and 93.7 for clarity, relevance and coherence, in first and second rounds, respectively. During the first round sixteen items were eliminated as they were not considered relevant by $\geq 80 \%$ of the experts. After the second round, seven items were eliminated, and the wording of a further four were improved as per the experts' recommendations. Finally, a set of 77 items was obtained which reached an agreement among the panel of $90 \%$ for clarity, and $95 \%$ for pertinence and relevance. Individual item scores are available in supplementary file 1. 
Table 1

Expert pannel profile

\begin{tabular}{|ll|}
\hline Gender & $\mathbf{n}(\%)$ \\
Men & $12(75)$ \\
\hline Age & $\mathbf{4}(25)$ \\
25 to 34 & $1(6.2)$ \\
35 to 44 & $6(37.5)$ \\
45 to 54 & $4(25)$ \\
55 to 64 & $4(25)$ \\
$\geq 65$ & $1(6.2)$ \\
\hline Professional field & \\
Midwifery & $6(37.5)$ \\
Nursing & $2(12.4)$ \\
Obstetrics & $5(31.2)$ \\
Psychology & $2(12.4)$ \\
Psychiatry & $1(6.2)$ \\
Professional Practice & \\
Clinical in Maternity Hospitals & $1(6.2)$ \\
Clinical in Primary Care & $4(25)$ \\
University Teaching and Research & \\
\hline
\end{tabular}

In order to detect problems of interpretation of the prototype and to assess the understanding of the questions and the included instructions, an online version was piloted with 30 subjects (students). Overall feedback was very positive, and no comprehension problems were reported. The prototype was then issued to a further 160 students who were in the final year of a degree in medicine at the University of Malaga. One hundred and 56 students completed the questionnaire (response rate of 97.5\%). The average age of the students was 23.9 years (SD 2.0; range 23-37), most of them were women (70.5\%) and only two of them had been pregnant and had children. The internal consistency of the 77-item prototype obtained a Cronbach's alpha of 0.83 and a Gutman's split half coefficient of 0.74 . Analysis of the correlations between the items and the overall score produced a final 52-item scale, called CAVE-st (acronym for cuestionario de actitudes sobre vivencias y experiencias en el parto), with an improved Cronbach's alpha of 0.92 and a Gutman's split half coefficient of 0.85 . The Cronbach's coefficient scores based on the inclusion and exclusion of items has been included in supplementary file 2.

The final 52-item version of CAVE-st asked participants to rate their agreement between 1 (completely disagree) and 5 (completely agree) to positively framed questions (item $4,9,11-15,17,20,21,24-45,49,51,52$ ) and between 1 (completely agree) and 5 (completely disagree) to negatively framed questions (item $1-3,5-8,10,16,18,19,22,23,46-48,50)$. The final CAVE-st score ranges between 52 and 260.

The mean, median and mode scores, the standard deviation and 25th, 50th and 75th percentiles from the sample of 156 students are shown in Table 2 . We did not find differences according to the age or gender of respondents. 
Table 2

Judges'agreement outcomes in both Delphi rounds. In dark the scores from second round

\begin{tabular}{|c|c|c|c|c|c|c|c|c|c|c|c|}
\hline ITEM & CLARITY & CLARITY & RELEVANCE & RELEVANCE & COHERENCE & COHERENCE & ITEM & CLARITY & CLARITY & RELEVANCE & RELEVANC \\
\hline 1 & 75 & 92.9 & 78.6 & 92.9 & 93.3 & 93.3 & 49 & 75 & 85.7 & 86 & 92.3 \\
\hline 2 & 82 & 92.9 & 86.7 & 93.3 & 86.7 & 86.7 & 50 & 69 & 46.7 & 73 & 92.9 \\
\hline 3 & 50 & 57.1 & 74 & 100 & 65 & 76.9 & 51 & 93 & 100 & 93 & 92.9 \\
\hline 4 & 62 & 71.4 & 70 & 85.7 & 64 & 76.9 & 52 & 75 & 92.3 & 79 & 100 \\
\hline 5 & 75 & 85.7 & 86 & 92.9 & 64 & 84.6 & 53 & 69 & 71.4 & 71 & 84.6 \\
\hline 6 & 85 & 85.7 & 94 & 100 & 94 & 100 & 54 & 88 & 100 & 86 & 100 \\
\hline 7 & 56 & 92.9 & 80 & 92.9 & 71 & 92.3 & 55 & 81 & 100 & 86 & 100 \\
\hline 8 & 80 & 80 & 79 & 92.3 & 79 & 92.3 & 56 & 87 & 100 & 93 & 100 \\
\hline 9 & 86 & 85.7 & 86 & 92.9 & 86 & 92.3 & 57 & 69 & 78.6 & 71 & 92.3 \\
\hline 10 & 81 & 85.7 & 86 & 100 & 79 & 100 & 59 & 75 & 80 & 71 & 84.6 \\
\hline 11 & 81 & 86.7 & 71 & 84.6 & 71 & 92.3 & 60 & 69 & 71.4 & 79 & 92.9 \\
\hline 12 & 75 & 86.7 & 71 & 76.9 & 71 & 92.3 & 61 & 69 & 85.7 & 79 & 85.7 \\
\hline 13 & 81 & 92.9 & 87 & 92.9 & 81 & 100 & 62 & 62 & 85.7 & 80 & 92.3 \\
\hline 14 & 69 & 71.4 & 79 & 92.3 & 86 & 100 & 63 & 93 & 92.9 & 93 & 92.3 \\
\hline 15 & 81 & 86.7 & 79 & 92.3 & 79 & 92.3 & 64 & 93 & 93.3 & 93 & 92.3 \\
\hline 16 & 69 & 71.4 & 79 & 92.3 & 85 & 85.7 & 68 & 93 & 93.3 & 80 & 92.3 \\
\hline 17 & 69 & 64.3 & 79 & 92.3 & 86 & 92.9 & 69 & 87 & 93.3 & 80 & 92.3 \\
\hline 18 & 88 & 92.9 & 87 & 100 & 86 & 92.3 & 70 & 75 & 71.4 & 73 & 92.3 \\
\hline 19 & 75 & 92.9 & 87 & 100 & 86 & 100 & 71 & 81 & 100 & 87 & 100 \\
\hline 20 & 88 & 100 & 93 & 100 & 93 & 92.9 & 73 & 88 & 100 & 87 & 92.9 \\
\hline 21 & 70 & 85.7 & 79 & 92.3 & 93 & 92.9 & 75 & 88 & 100 & 87 & 100 \\
\hline 22 & 88 & 100 & 93 & 100 & 100 & 92.9 & 76 & 94 & 100 & 87 & 100 \\
\hline 23 & 69 & 64.3 & 71 & 92.3 & 79 & 92.9 & 77 & 88 & 100 & 87 & 100 \\
\hline 24 & 81 & 78.6 & 86 & 85.7 & 86 & 84.6 & 78 & 88 & 100 & 87 & 92.3 \\
\hline 25 & 81 & 85.7 & 79 & 92.3 & 79 & 100 & 79 & 94 & 85.7 & 100 & 100 \\
\hline 26 & 81 & 85.7 & 80 & 92.3 & 86 & 93.3 & 80 & 100 & 85.7 & 100 & 100 \\
\hline 27 & 87 & 93.3 & 86 & 92.3 & 86 & 92.3 & 81 & 88 & 100 & 87 & 100 \\
\hline 28 & 75 & 78.6 & 73 & 84.6 & 79 & 85.7 & 82 & 80 & 80 & 80 & 92.3 \\
\hline 29 & 81 & 86.7 & 71 & 84.6 & 71 & 100 & 83 & 81 & 100 & 87 & 100 \\
\hline 31 & 73 & 73.3 & 71 & 84.6 & 64 & 76.9 & 84 & 94 & 100 & 93 & 100 \\
\hline 32 & 100 & 100 & 100 & 100 & 100 & 100 & 85 & 94 & 100 & 93 & 100 \\
\hline 33 & 69 & 71.4 & 80 & 85.7 & 69 & 76.9 & 86 & 100 & 100 & 100 & 100 \\
\hline 34 & 69 & 64.3 & 79 & 85.7 & 79 & 84.6 & 87 & 93 & 100 & 93 & 100 \\
\hline 36 & 75 & 86.7 & 73 & 100 & 73 & 100 & 88 & 62 & 64.3 & 73 & 84.6 \\
\hline 37 & 87 & 100 & 87 & 100 & 93 & 100 & 90 & 93 & 100 & 73 & 84.6 \\
\hline 38 & 100 & 100 & 100 & 100 & 100 & 92.9 & 95 & 81 & 86.7 & 73 & 76.9 \\
\hline 39 & 86 & 85.7 & 86 & 92.9 & 86 & 100 & 96 & 81 & 80 & 80 & 66.7 \\
\hline 43 & 69 & 85.7 & 71 & 100 & 71 & 100 & 97 & 87 & 100 & 93 & 100 \\
\hline 45 & 69 & 85.7 & 80 & 100 & 80 & 100 & 98 & 87 & 100 & 93 & 100 \\
\hline 46 & 81 & 100 & 80 & 92.3 & 80 & 92.3 & 99 & 94 & 100 & 93 & 100 \\
\hline 47 & 75 & 93.3 & 73 & 92.3 & 71 & 92.3 & & & & & \\
\hline
\end{tabular}


Finally, the test-retest reliability was assessed in a sample of 60 students with a further version of the questionnaire completed two weeks after it was first completed. A Spearman correlation index $r=0.73$ and a significant intraclass correlation coefficient $r=0.864(F$ 7.30. df59. $p<0.0001)$ confirmed its reliability.

\section{Exploratory factorial analysis}

The Kaiser-Meyer-Olkin measure was 0.704 and the Bartlett's test of sphericity was favourable (Chi-Square 2731.90. df13780. p < 0.0001 ). The exploratory factory analysis revealed sixteen components that explained $70.6 \%$ of the variance (Tables $3-5$ ). While one of the components (Component 1 ) explained $21.827 \%$ of the total variance, the rest ranged between $5.7 \%$ and $1.9 \%$. Table 3 shows the proportion of the total variance explained by each main component. Table 4 includes the distribution of items and their saturation in each component. As shown, components 1 to 16 were defined by a different number of items, with the range from 1-8 items. Component 1 assesses the students' beliefs about the psychosocial factors that could influence women's experience of birth, specifically it consists of 8 items regarding women's mental health, previous obstetric trauma, the perception of support from birth partners, and the role of social, family or economic resources. Component 2 assesses a dimension related to women's empowerment and includes three items about women's consent and the students' idealization of women's physical and psychological strength. Component 3 includes two items that relate to the students' role identity, and the image that they should show to others in perinatal scenarios. Component 4 consists of 6 items regarding students' opinion about the influence of obstetric complications (obstetric haemorrhage, caesarean section, foetal demise, or uncontrollable pain) during labour on women's experience of birth, and birth trauma. Component 5 includes 5 items, that assess the role of hypothetical unexpected events like a preterm birth or a medical diagnosis on women's experience. Component 6 consists of three items that explore the students' attitudes on women's expectations of a normal birth. Component 7 comprises 3 items assessing students' ability to detect and/or prevent a birth trauma. Component 8 assesses the student's attitude towards women's need for accompaniment during birth and includes 3 items. Component 9 consists of 3 items that assess students' ability to empathize with women. Component 10 comprises three items that focus on students' attitudes towards women's decision-making processes during labour. Component 11 consists of five items that evaluate student's attitudes regarding medicalization of birth. Component 12 includes two items that measure the student's self-awareness of how they may influence birth and the responsibility they have towards women. Component 13 consists of 2 items that assess students' respect for women's freedom to choose different alternatives during childbirth. Component 14 comprises 2 items that measure students' attitudes towards how care should be prioritized during childbirth. Components 15 and 16 only included 1 item each, and while these items could have been suitable to group with other components, the statistics identified them as independent factors. In Component 15 the item assessed the role of birth trauma as a risk factor for breastfeeding difficulties, in Component 16, the item assessed student's attitudes towards continuous cardiotocography during normal childbirth. After the analysis, and following logical and clinical criteria, these single items from Components 15 and 16, were added to Components 7 and 11 respectively, in which they also showed moderate saturations. Table 5 shows the correlations between the components, and with overall scores, Table 6 shows the score limits for the global scale and for the 14 components, as well as the distribution of scores in the sample of 156 students. Supplementary file 3 includes the items distribution among the components.

Table 3

Outcomes for the exploratory factorial analysis

\begin{tabular}{|c|c|c|c|c|c|c|c|c|c|}
\hline \multicolumn{10}{|c|}{ Total variance explained } \\
\hline \multirow[t]{2}{*}{ Components } & \multicolumn{3}{|c|}{ Initial Eigenvalues } & \multicolumn{3}{|c|}{ Extraction sums of squared loadings } & \multicolumn{3}{|c|}{ Rotation sums of squared loadings } \\
\hline & Total & $\begin{array}{l}\% \text { of the } \\
\text { Variance }\end{array}$ & $\begin{array}{l}\text { Cumulative } \\
\%\end{array}$ & Total & $\begin{array}{l}\% \text { of the } \\
\text { Variance }\end{array}$ & $\begin{array}{l}\text { Cumulative } \\
\%\end{array}$ & Total & $\begin{array}{l}\% \text { of the } \\
\text { Variance }\end{array}$ & $\begin{array}{l}\text { Cumulative } \\
\%\end{array}$ \\
\hline 1 & 11.568 & 21.827 & 21.827 & 11.568 & 21.827 & 21.827 & 4.303 & 8.120 & 8.120 \\
\hline 2 & 3.052 & 5.759 & 27.586 & 3.052 & 5.759 & 27.586 & 3.187 & 6.013 & 14.133 \\
\hline 3 & 2.577 & 4.862 & 32.448 & 2.577 & 4.862 & 32.448 & 2.821 & 5.322 & 19.455 \\
\hline 4 & 2.131 & 4.021 & 36.469 & 2.131 & 4.021 & 36.469 & 2.808 & 5.299 & 24.754 \\
\hline 5 & 2.063 & 3.893 & 40.362 & 2.063 & 3.893 & 40.362 & 2.690 & 5.075 & 29.829 \\
\hline 6 & 1.949 & 3.677 & 44.039 & 1.949 & 3.677 & 44.039 & 2.553 & 4.817 & 34.646 \\
\hline 7 & 1.869 & 3.526 & 47.565 & 1.869 & 3.526 & 47.565 & 2.321 & 4.379 & 39.025 \\
\hline 8 & 1.796 & 3.389 & 50.954 & 1.796 & 3.389 & 50.954 & 2.242 & 4.231 & 43.256 \\
\hline 9 & 1.641 & 3.097 & 54.051 & 1.641 & 3.097 & 54.051 & 2.219 & 4.186 & 47.442 \\
\hline 10 & 1.527 & 2.881 & 56.932 & 1.527 & 2.881 & 56.932 & 2.015 & 3.802 & 51.245 \\
\hline 11 & 1.458 & 2.752 & 59.683 & 1.458 & 2.752 & 59.683 & 2.011 & 3.795 & 55.039 \\
\hline 12 & 1.256 & 2.370 & 62.053 & 1.256 & 2.370 & 62.053 & 1.905 & 3.595 & 58.634 \\
\hline 13 & 1.225 & 2.312 & 64.365 & 1.225 & 2.312 & 64.365 & 1.697 & 3.202 & 61.836 \\
\hline 14 & 1.168 & 2.203 & 66.568 & 1.168 & 2.203 & 66.568 & 1.667 & 3.145 & 64.982 \\
\hline 15 & 1.114 & 2.102 & 68.670 & 1.114 & 2.102 & 68.670 & 1.523 & 2.873 & 67.855 \\
\hline 16 & 1.030 & 1.944 & 70.614 & 1.030 & 1.944 & 70.614 & 1.463 & 2.759 & 70.614 \\
\hline
\end{tabular}


Table 4

Distribution of items and coefficients for each main component in the prototype. (C1: Psychosocial Factors; C2: Women's empowerment; C3: Role identity; C. Obstetric Trauma; C8: Accompaniment; C9: Empathy; C10: Women's decisions; C11:Medicalization; C12: Commitment

\begin{tabular}{|c|c|c|c|c|c|c|c|c|c|c|c|c|c|c|c|c|c|c|c|c|}
\hline \multicolumn{2}{|l|}{ C1 } & \multirow{2}{*}{$\begin{array}{l}\text { C2 } \\
38\end{array}$} & \multicolumn{2}{|c|}{ C3 } & \multicolumn{2}{|c|}{ C4 } & \multicolumn{2}{|c|}{ C5 } & \multicolumn{2}{|c|}{ C6 } & \multicolumn{2}{|c|}{ C7 } & \multicolumn{2}{|c|}{ C8 } & \multicolumn{2}{|c|}{ C9 } & \multicolumn{2}{|c|}{ C10 } & \multicolumn{2}{|c|}{ C11 } \\
\hline 79 & 0.792 & & 0.769 & 32 & 0.846 & 14 & 0.768 & 84 & 0.753 & 53 & 0.749 & 61 & 0.607 & 23 & 0.804 & 18 & 0.76 & 46 & 0.821 & 2 \\
\hline 80 & 0.743 & 37 & 0.745 & 33 & 0.727 & 13 & 0.64 & 85 & 0.681 & 95 & 0.669 & 59 & 0.456 & 24 & 0.637 & 63 & 0.526 & 45 & 0.541 & 68 \\
\hline 81 & 0.597 & 90 & 0.583 & & & 71 & 0.464 & 73 & 0.484 & 51 & 0.432 & 57 & 0.331 & 25 & 0.403 & 47 & 0.416 & 15 & 0.406 & 55 \\
\hline 78 & 0.592 & & & & & 75 & 0.45 & 77 & 0.456 & & & & & & & & & & & 12 \\
\hline 82 & 0.576 & & & & & 52 & 0.313 & 87 & 0.376 & & & & & & & & & & & 69 \\
\hline 83 & 0.556 & & & & & 76 & 0.44 & & & & & & & & & & & & & 54 \\
\hline 86 & 0.534 & & & & & & & & & & & & & & & & & & & \\
\hline 62 & 0.393 & & & & & & & & & & & & & & & & & & & \\
\hline
\end{tabular}

Table 5

Pearson's correlations coefficients betwen the components and CAVE st scores (NS: sot significant; C1:Psychosocial Factors; C2: Women's empowerment; C3: Role identity; C4: Complications; C5: Unexpected outcomes; C6: Women's expectations; C7: Obstetric Trauma; C8: Accompaniment; C9: Empathy; C10: Women 's decisions; C11:Medicalization; C12: Commitment; C13: Respect; C14: Clinical priorities)

\begin{tabular}{|c|c|c|c|c|c|c|c|c|c|c|c|c|c|c|c|}
\hline & CAVE st & C1 & $\mathrm{C} 2$ & C3 & $\mathrm{C4}$ & C5 & $\mathrm{C6}$ & C7 & $\mathrm{C8}$ & $\mathrm{Cg}$ & $\mathrm{C} 10$ & $\mathrm{C} 11$ & $\mathrm{C} 12$ & $\mathrm{C13}$ & $\mathrm{C} 14$ \\
\hline C1. Psychosocial Factors & 0.76 & 1 & & & & & & & & & & & & & \\
\hline $\begin{array}{l}\text { C2. Women's } \\
\text { empowerment }\end{array}$ & 0.53 & 0.40 & 1 & & & & & & & & & & & & \\
\hline C3. Role identity & 0.43 & 0.18 & 0.20 & 1 & & & & & & & & & & & \\
\hline C4. Complications & 0.60 & 0.31 & NS & 0.19 & 1 & & & & & & & & & & \\
\hline C5. Unexpected outcomes & 0.60 & 0.56 & 0.20 & 0.22 & 0.32 & 1 & & & & & & & & & \\
\hline c6. Women's expectations & 0.57 & 0.41 & 0.24 & 0.28 & 0.32 & 0.27 & 1 & & & & & & & & \\
\hline C7. Obstetric Trauma & 0.45 & 0.19 & NS & NS & 0.37 & 0.17 & 0.27 & 1 & & & & & & & \\
\hline C8. Accompaniment & 0.42 & 0.23 & 0.18 & 0.27 & 0.24 & NS & 0.22 & NS & 1 & & & & & & \\
\hline C9. Empathy & 0.46 & 0.36 & 0.36 & 0.15 & NS & 0.29 & 0.26 & NS & NS & NS & & & & & \\
\hline C10. Women's decisions & 0.40 & NS & 0.41 & 0.15 & NS & NS & NS & NS & NS & 0.37 & 1 & & & & \\
\hline C11. Medicalization & 0.47 & 0.32 & NS & 0.17 & 0.22 & 0.27 & 0.19 & 0.26 & NS & NS & NS & 1 & & & \\
\hline C12. Commitment & 0.47 & 0.39 & 0.26 & NS & NS & 0.28 & 0.19 & 0.17 & NS & 0.17 & 0.17 & 0.28 & 1 & & \\
\hline C13. Respect & 0.33 & NS & NS & NS & 0.24 & NS & 0.15 & 0.22 & NS & NS & 0.17 & NS & NS & 1 & \\
\hline C14. Clinical priorities & 0.29 & NS & NS & NS & 0.25 & NS & NS & 0.16 & NS & NS & NS & NS & NS & 0.25 & 1 \\
\hline
\end{tabular}


Table 6

CAVE st Scale and its components. Limits and scores in the sample $\mathrm{n}=156$ students. Min. = Minimum; Max. = Maximum; Std E.M: Standard error of the Mean Std Dev: Standard Deviation; P: Percentile; Q: Quartile

\begin{tabular}{|c|c|c|c|c|c|c|c|c|c|c|c|c|c|c|c|c|}
\hline \multirow[t]{2}{*}{ Scale/Components } & \multirow[t]{2}{*}{ Items } & \multicolumn{2}{|c|}{ Range } & \multicolumn{13}{|c|}{$\begin{array}{l}\text { Scores } \\
(n=156)\end{array}$} \\
\hline & & $\begin{array}{l}\text { Min } \\
\text { Ma: }\end{array}$ & & Min. & Max. & Mode & Median & Mean & $\begin{array}{l}\text { Std } \\
\text { E.M. }\end{array}$ & $\begin{array}{l}\text { Std } \\
\text { Dev }\end{array}$ & $P_{5}$ & $P_{15}$ & $\mathrm{Q}_{1}$ & Q3 & $P_{85}$ & $P_{95}$ \\
\hline CAVE st Scale & $\begin{array}{l}\text { GLOBAL } \\
\text { SCALE }\end{array}$ & 52 & 260 & 172 & 244 & 204 & 204 & 205.5 & 10.16 & 140.55 & 180 & 191 & 195 & 215 & 221 & 233,15 \\
\hline $\begin{array}{l}\text { C1. Psychosocial } \\
\text { Factors }\end{array}$ & $\begin{array}{l}25 ; 36 ; \\
37 ; 38 ; \\
39 ; 40 ; \\
41 ; 44\end{array}$ & 9 & 45 & 24 & 40 & 31 & 34 & 33,91 & 0.31 & 3,88 & 27 & 30 & 31 & 37 & 38 & 40 \\
\hline $\begin{array}{l}\text { C2. Women's } \\
\text { empowerment }\end{array}$ & $\begin{array}{l}11 ; 12 \\
49\end{array}$ & 3 & 15 & 8 & 15 & 15 & 13 & 12,97 & 0.15 & 1,87 & 9 & 11 & 12 & 15 & 15 & 15 \\
\hline C3. Role identity & $9 ; 10$ & 3 & 15 & 5 & 10 & 10 & 10 & 8,97 & 0.11 & 1,42 & 6 & 7 & 8 & 10 & 10 & 10 \\
\hline C4. Complications & $\begin{array}{l}\text { 1; } 2 ; 18 \\
31 ; 33 \\
34\end{array}$ & 5 & 25 & 14 & 30 & 25 & 23 & 22,66 & 0.22 & 2,79 & 18 & 20 & 21 & 25 & 25 & 27 \\
\hline $\begin{array}{l}\text { C5. Unexpected } \\
\text { outcomes }\end{array}$ & $\begin{array}{l}32 ; 35 \\
42 ; 43 \\
45\end{array}$ & 4 & 25 & 15 & 25 & 21 & 22 & 21,64 & 0.17 & 2,24 & 18 & 19 & 20 & 23 & 24 & 25 \\
\hline $\begin{array}{l}\text { C6. Women's } \\
\text { expectations }\end{array}$ & $\begin{array}{l}50 ; 17 \\
19\end{array}$ & 3 & 15 & 7 & 15 & 13 & 13 & 12,94 & 0.13 & 1,71 & 10 & 11 & 12 & 14 & 15 & 15 \\
\hline $\begin{array}{l}\text { C7. Obstetric } \\
\text { Trauma }\end{array}$ & $\begin{array}{l}22 ; 23 \\
24\end{array}$ & 3 & 15 & 9 & 20 & 14 & 14 & 14,18 & 0.16 & 2,0 & 11 & 12 & 13 & 15 & 16 & 18 \\
\hline $\begin{array}{l}\text { C8. } \\
\text { Accompaniment }\end{array}$ & $6 ; 7 ; 8$ & 3 & 15 & 6 & 15 & 13 & 13 & 12,27 & 0.16 & 2,01 & 8 & 10 & 11 & 14 & 14 & 15 \\
\hline C9. Empathy & $26 ; 15 ; 4$ & 3 & 15 & 8 & 15 & 13 & 13 & 12,67 & 0.12 & 1,60 & 10 & 11 & 12 & 14 & 14,4 & 15 \\
\hline $\begin{array}{l}\text { C10. Women's } \\
\text { decisions }\end{array}$ & $3 ; 13 ; 14$ & 3 & 15 & 5 & 15 & 11 & 11 & 11,01 & 0.16 & 2,11 & 7 & 9 & 10 & 12 & 13 & 15 \\
\hline $\begin{array}{l}\text { C11. } \\
\text { Medicalization }\end{array}$ & $\begin{array}{l}20 ; 21 ; \\
28 ; 29 \\
46 ; 48\end{array}$ & 6 & 30 & 14 & 25 & 18 & 19 & 18.74 & 0.17 & 2,12 & 15 & 17 & 19 & 20 & 21 & 23 \\
\hline C12. Commitment & $\begin{array}{l}27 ; 51 \\
52\end{array}$ & 3 & 15 & 8 & 15 & 13 & 12 & 12,04 & 0.12 & 1,50 & 9,8 & 10 & 11 & 13 & 13 & 15 \\
\hline $\begin{array}{l}\text { C13. Decision } \\
\text { making }\end{array}$ & $30 ; 47$ & 2 & 10 & 4 & 10 & 6 & 6 & 6,42 & 0.09 & 1,23 & 4,8 & 5 & 6 & 7 & 8 & 9 \\
\hline $\begin{array}{l}\text { C14. Clinical } \\
\text { priorities }\end{array}$ & $5 ; 16$ & 2 & 10 & 2 & 10 & 6 & 5 & 5,07 & 0.12 & 1,52 & 3 & 3 & 5 & 6 & 6,4 & 7 \\
\hline
\end{tabular}

Overall, women scored significantly higher in Component 6 [13,1 (SD 1.9) against 12.5 (SD 1.5), t-Student - 2.1; 154 df; $p<0.03$ in male students], and Component 8 [12.6 (SD 1.7) against 11.4 (SD 2.2); t-Student - 3.2; $69 \mathrm{df} ; \mathrm{p}<0.002$ in male students], but no other sociodemographic differences were found for the remaining components (Table 6).

\section{Discussion}

This article describes the development and validation processes of the Spanish version of CAVE-st, an instrument designed to measure health sciences students' attitudes towards women's childbirth experiences. CAVE-st resulted in a 52-item questionnaire that consists of 14 latent components which were related to four major dimensions, Beliefs regarding childbirth, Knowledge on childbirth related trauma, Recognition of childbirth related trauma, and Childbirth related performance. The psychometric analyses revealed that CAVE-st is a reliable and valid tool to use in health science academic contexts. This questionnaire offers an important means to identify which dimensions of psychosocial care need to be improved in the perinatal syllabus, to promote better care for women at childbirth.

A number of studies have been published in the last decade that explore incorporating specific competencies or pedagogical interventions in medical, nursing or midwifery study programs to improve the quality of woman-professional interactions during the perinatal period (18, 19, 28-30, 20-27). Most of these studies are surveys conducted among education experts and programme directors, with particular attention to training needs in relation to dignity, respect (27, 30) and perinatal mental health (20). Regarding undergraduate students, some authors have proposed interprofessional education initiatives, involving midwives and nurses as teachers to develop communication and support skills $(18,29)$. These studies involved training first-year medical students that provided clinical and non-clinical care to pregnant women, and the training covered issues such as paying attention to women instead of the electronic instruments in the delivery room, speaking in an appropriate tone, attending to women's needs, and providing emotional or physical support (20, 23). The 
CAVE-st questionnaire that we have developed and validated could be a useful tool to identify specific dimensions to target during the training, and a method to assess students' learning. It could also be useful to reveal educational needs in offering women individualized attention (31), or the meta-cognitive skills needed for effective communication (32).

CAVE-st may also be useful to assess students' perception of risk in perinatal scenarios. Student's perception of risk or safety of the clinical situation can differ from the perspective of the woman, and also from other members of the care team. This is largely due to assessments being based on subjective, rather than objective and measurable indicators (33). How students complete the questionnaire could thereby help to highlight how they value the need for implicit communication in determining the risks or certainties perceived by others (34). Also, our tool has the advantage of including the theoretical and practical aspects of birth related trauma and perinatal mental health $(20,35-38)$.

During labour and birth, humanity and compassion are essential elements of a woman's care, and especially in cases with complications (39). Many factors can hinder professionals' providing person-centred care (40) such as the need to protect the safety of the mother and the foetus, irrespective of a woman's preferred birthing choices. Efforts should be aimed at fostering environments in which, in addition to pursuing the best possible obstetric and perinatal outcomes, women feel in control of the situation, safe and respected (41) For this purpose, CAVE-st may be an useful tool.

\section{Limitations And Strengths}

Some limitations need to be considered. First, as this is the first instrument to assess students' attitudes towards childbirth, we could not compare our results with any other published results. Second, the validation was based on the responses of a large homogenous sample of medical students, rather than wider health science students which may have weakened the reported psychometric properties. Posterior assessments in heterogeneous samples including nursing and midwifery students will improve validation results.

The strengths are that the development and validation of CAVE-st followed systematic and standard procedures, with a Delphi consensus and three different assessments undertaken. The collaboration with international and multidisciplinary academics in the design and execution of this study also strengthens our findings.

\section{Conclusions}

This study provides detailed insights into the development and psychometric properties of the Spanish version of the Cave-st questionnaire. Cave-st is the first questionnaire to assess health science students' attitudes of key factors that can impact on women's birth experiences. The results show that Cave-st is a valid and reliable tool and

further work is planned to translate, adapt and apply the instrument in other cultures and languages to capture international evidence. Cave-st can help identify what dimensions need to be integrated and reinforced in perinatal training programs, to compare variations in different pre-registration programmes and in different settings, and ultimately to help design optimum training programmes to improve women's experience of childbirth, and to avoid birth related trauma.

\section{Declarations}

\section{Ethics approval and consent to participate}

Ethical approval was obtained from CEI de la Provincia de Malaga. All the students participated voluntarily and gave their online written consent to participate.

\section{Consent for publication}

All authors agreed on the publication of this research

\section{Availability of data and materials}

The datasets used and/or analysed during the current study are available from the corresponding author on reasonable request.

\section{Competing interests}

Authors do not have any competing interest to declare.

\section{Funding}

This study was carried out with the support of the COST Action - CA 18211: Perinatal Mental Health and Birth-Related Trauma: Maximising best practice and optimal outcomes.

\section{Author contributions}

Conceptualization: EGM, CRD, SIK, OR, GT, WA, OCG, GGI. Methodology: EGM,CR, OR, WA, DMN, SIK, SSJ, GT, JL, GGI; Formal analysis and investigation: CRD, OCG, EGM, WA, DMN, GGI, GT, OR, SSJ, SIK; Writing - original draft preparation: EGM, CRD, OR, OCG, JL, SIK, GT, DMN, WA; Writing - review and editing: GT, JL, WA, OR, SIK, ; Resources: CRD, EGM, OCG; Supervision: JL, OR, SIK, GT, WA, JL. 
We appreciate the work of the expert group that participated in the Delphi panel, as well as the students that completed the assessments.

\section{References}

1. Rosenstein AH, O'Daniel M. A survey of the impact of disruptive behaviors and communication defects on patient safety. Jt Comm J Qual Patient Saf. 2008.

2. Sorenson DS, Tschetter L. Prevalence of negative birth perception, disaffirmation, perinatal trauma symptoms, and depression among postpartum women. Perspect Psychiatr Care. 2010.

3. Sando D, Abuya T, Asefa A, Banks KP, Freedman LP, Kujawski S, et al. Methods used in prevalence studies of disrespect and abuse during facility based childbirth: Lessons learned Prof. Suellen Miller. Reproductive Health. 2017.

4. Afulani PA, Moyer CA. Accountability for respectful maternity care. The Lancet. 2019.

5. Simpson M, Catling C. Understanding psychological traumatic birth experiences: A literature review. Women and Birth. 2016.

6. Meaney S, Lutomski JE, O'Connor L, O'Donoghue K, Greene RA. Women's experience of maternal morbidity: A qualitative analysis. BMC Pregnancy Childbirth. 2016.

7. Rijnders M, Baston H, Schönbeck Y, Van Der Pal K, Prins M, Green J, et al. Perinatal factors related to negative or positive recall of birth experience in women 3 years postpartum in the Netherlands. Birth. 2008.

8. Stramrood CAI, Paarlberg KM, Huis In 'T, Veld EMJ, Berger LWAR, Vingerhoets AJJM, Weijmar Schultz WCM, et al. Posttraumatic stress following childbirth in homelike-and hospital settings. J Psychosom Obstet Gynecol. 2011.

9. Beck CT. Birth trauma: In the eye of the beholder. Nurs Res. 2004.

10. Ford E, Ayers S. Support during birth interacts with prior trauma and birth intervention to predict postnatal post-traumatic stress symptoms. Psychol Heal. 2011.

11. Yildiz PD, Ayers S, Phillips L. The prevalence of posttraumatic stress disorder in pregnancy and after birth: A systematic review and meta-analysis. Journal of Affective Disorders. 2017.

12. O'Connell MA. Preventing, recognising, and responding to fear of childbirth and birth trauma. The BMJ. 2019.

13. World Health Organization. The prevention and elimination of disrespect and abuse during facility-based childbirth: WHO statement. World Heal Organ. 2015.

14. Warren CE, Njue R, Ndwiga C, Abuya T, Kabo JW, SuellenMilleraAndreLalonde, et al. WHO recommendations: Intrapartum care for a positive childbirth experience. BMC Pregnancy Childbirth. 2018.

15. Petit-Steeghs V, Lips SR, Schuitmaker-Warnaar TJ, Broerse JEW. Client-centred maternity care from women's perspectives: Need for responsiveness. Midwifery. 2019

16. Jones J, Hunter D. Consensus methods for medical and health services research. Br Med J. 1995.

17. Murphy B, Lamping McKee, Sanderson A, et al. Consensus development methods, and their use in clinical guideline development. Health Technol Assess (Rockv). 1998.

18. Cooksey NR. Bridging the Gap Between Textbook and Maternity Patient: A Nurse-Developed Teaching Model for First-Year Medical Students. Birth. 2010.

19. Daboval T, Ferretti E, Moussa A, Van Manen M, Moore GP, Srinivasan G, et al. Needs assessment of ethics and communication teaching for neonatal perinatal medicine programs in Canada. Paediatr Child Heal. 2019.

20. Garbarino AH, Kohn JR, Coverdale JH, Kilpatrick CC. Current Trends in Psychiatric Education Among Obstetrics and Gynecology Residency Programs. Acad Psychiatry. 2019.

21. Thompson SM, Nieuwenhuijze MJ, Low LK, De Vries R. Creating Guardians of Physiologic Birth: The Development of an Educational Initiative for Student Midwives in the Netherlands. J Midwifery Women's Heal. 2019.

22. Daboval T, Ferretti E, Moore GP. Innovative Holistic Teaching in a Canadian Neonatal Perinatal Residency Program. Hastings Cent Rep. 2014.

23. Cummings CL, Geis GM, Kesselheim JC, Sayeed S. Ethics and professionalism education during neonatal-perinatal fellowship training in the United States. J Perinatol. 2015.

24. Pilkenton D, Collins MR, Holley S. Teaching Labor Support: An Interprofessional Simulation. Journal of Midwifery and Women's Health. 2015.

25. Arzuaga BH, Cummings $\mathrm{CL}$. Practices and education surrounding anticipated periviable deliveries among neonatal-perinatal medicine and maternal-fetal medicine fellowship programs. J Perinatol. 2016.

26. Drake E. Challenges and creative strategies in undergraduate nursing education in maternal-child health. J Perinat Neonatal Nurs. 2016.

27. Hall J, Mitchell M. Dignity and respect in midwifery education in the UK: A survey of Lead Midwives of Education. Nurse Educ Pract. 2016.

28. Persson EK, Kvist LJ, Ekelin M. Midwifery students' experiences of learning through the use of written reflections - An interview study. Nurse Educ Pract. 2018.

29. Shakartzi H, Wenren L, Fernandes S, Marino R, Meade M, Pierre-Joseph N, et al. DREAM: Empowering Preclinical Medical Students With Labor Support. MedEdPORTAL J Teach Learn Resour. 2018.

30. Yin Y, Li J, Lu H, Yao J, Hou R. Essential competencies for three grades of midwives in China. Int J Nurs Sci. 2018. 
31. Leon-Larios F, Nuno-Aguilar C, Rocca-Ihenacho L, Castro-Cardona F, Escuriet R. Challenging the status quo: Women's experiences of opting for a home birth in Andalucia, Spain. Midwifery. 2019.

32. van Dinter-Douma EE, de Vries NE, Aarts-Greven M, Stramrood CAI, van Pampus MG. Screening for trauma and anxiety recognition: knowledge, management and attitudes amongst gynecologists regarding women with fear of childbirth and postpartum posttraumatic stress disorder. Journal of Maternal-Fetal and Neonatal Medicine. 2018.

33. de Melo-Martín I, Intemann K. Interpreting evidence: Why values can matter as much as science. Perspect Biol Med. 2012.

34. Lee S, Holden D, Webb R, Ayers S. Pregnancy related risk perception in pregnant women, midwives \& doctors: A cross-sectional survey. BMC Pregnancy Childbirth. 2019.

35. Hauck YL, Kelly G, Dragovic M, Butt J, Whittaker P, Badcock JC. Australian midwives knowledge, attitude and perceived learning needs around perinatal mental health. Midwifery. 2015.

36. Higgins A, Carroll M, Sharek D. Impact of perinatal mental health education on student midwives' knowledge, skills and attitudes: A pre/post evaluation of a module of study. Nurse Educ Today. 2016.

37. Noonan M, Doody O, O’Regan A, Jomeen J, Galvin R. Irish general practitioners' view of perinatal mental health in general practice: A qualitative study. BMC Fam Pract. 2018.

38. Coates D, Foureur M. The role and competence of midwives in supporting women with mental health concerns during the perinatal period: A scoping review. Health and Social Care in the Community. 2019.

39. Berg M. A Midwifery Model of Care for Childbearing Women at High Risk: Genuine Caring in Caring for the Genuine. J Perinat Educ. 2005.

40. Behruzi R, Hatem M, Goulet L, Fraser W, Leduc N, Misago C. Humanized birth in high risk pregnancy: Barriers and facilitating factors. Med Heal Care Philos. 2010.

41. Fontein-Kuipers Y, Koster D, Romijn C, Sakko E, Stam C, Steenhuis N, et al. I-POEMS Listening to the voices of women with a traumatic birth experience. J Psychol Cogn. 2018.

\section{Figures}

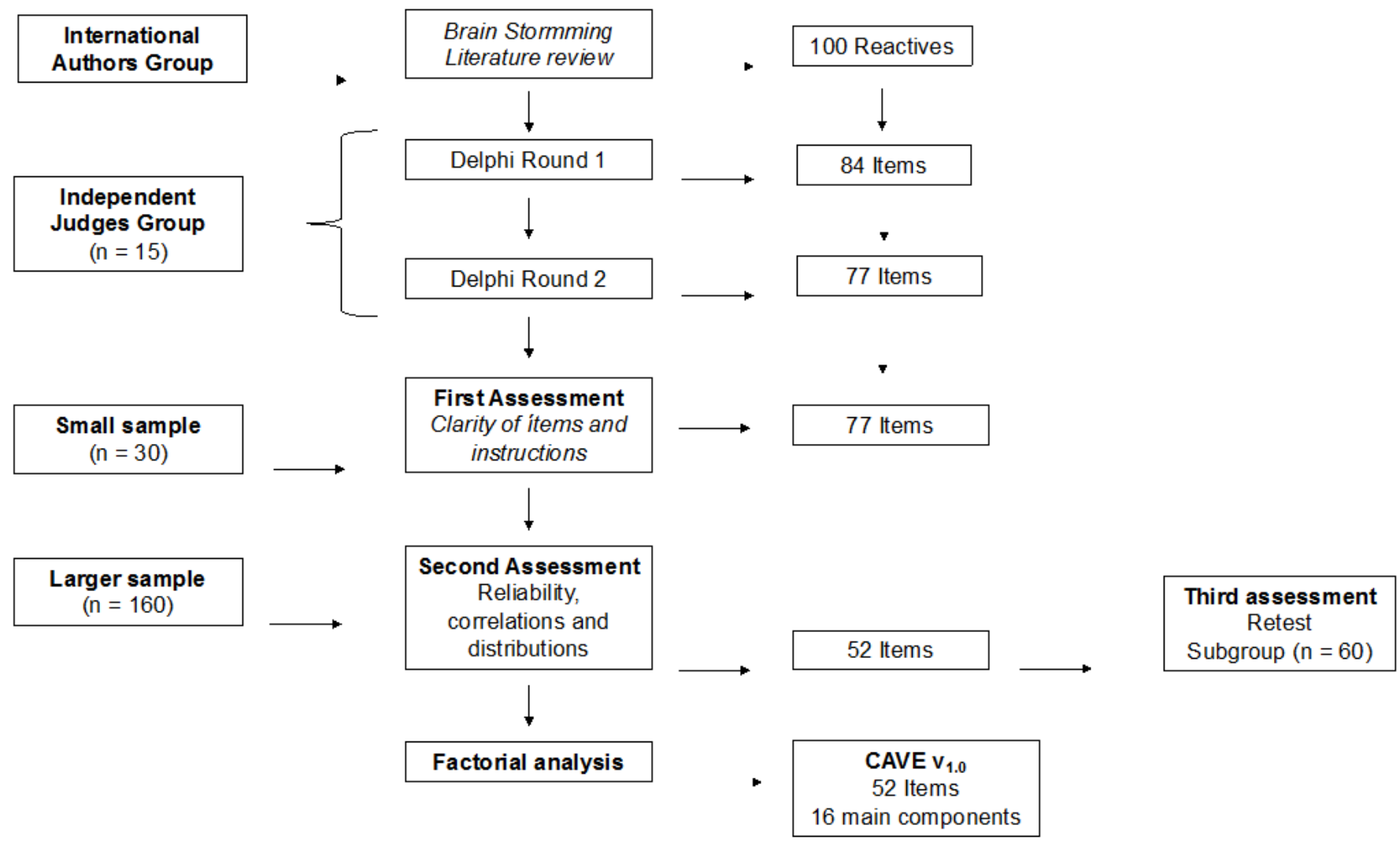

Figure 1

Flow diagram for development and validation of CAVE st 